\title{
The Influencing Factors of Labor Force Wages in China-Based on Empirical Analysis of Mincer Wage Equation
}

\author{
Yuyang Zhu \\ School of mathematical Sciences, Zhejiang University, HangZhou310000, China. \\ ddbbcasdo@163.com
}

\begin{abstract}
Based on the extended Mincer Wage Equation, the thesis uses OLS method to conduct concrete regression analysis of the factors influencing wages. It also uses the data from the followup survey report carried out by China Family Panel Studies (CFPS) in 2014. The estimated results suggest that compared with other academic levels, junior college education or above has a much greater effect on salary income. In addition, gender discrimination still extremely exists in various regions. Household registration discrimination is mainly concentrated in eastern region. The member of Communist Party of China does not have a significant impact on salary income.
\end{abstract}

Keywords: Mincer Wage Equation, CFPS, empirical analysis, OLS method.

\section{Introduction}

\subsection{Research Background and Significance}

Since reform and opening up, the economy of China has achieved tremendous growth, and distribution mode has also gradually changed from distribution according to demand to distribution according to work. The country no longer uses the unified wage standards, and income distribution is gradually diversified. However, the transition has also resulted in corresponding problems. For instance, the wealth gap has gradually enlarged. Industry factors have more obvious impact on income. Besides, there are also problems such as irrational distribution of educational resources and increasing discrimination.

The wage level is a significant indicator that reflects the economic situation of China. It can effectively reflect the circumstances and existing problems in China labor market, thus shedding light on which factor plays a leading role in determining income. Education is the most significant factor in determining the wage of labor force. The rate of return to education directly reflects China's ability to transform education investment into human resources. With the gradual popularization of higher education, college graduates are faced with more and more difficult problems in finding jobs. Hence, people gradually pay more attention to the rate of return to education. Other factors such as regional and gender differences also have a large effect on the wage level. Via calculating the effects of various factors on wages by linear regression method, we can gain a deeper insight into the current situation of China's labor market, and give relevant policy suggestions to some current problems.

\subsection{Literature Review}

Mincer proposed the standard form of classic wage equation in 1974, pointing out that human resources factors such as education and working experiences ought to be taken into account in the process of considering wage, which laid a foundation for studying the influencing factors of wages. Additionally, according to Becker's theory of discrimination, discrimination exists in many employers' recruitment and payment, such as the preference of urban hukou (household registration) and the rejection of female job seekers. Therefore, these factors should also be taken into consideration when determining the extended wage equation. At present, there are already many studies of wage levels in China, revealing lots of important factors and characteristics that may influence wage levels. For instance, even though the migrant labor force and the urban local labor force work in the same position, their wages can be different [1].Studies have already shown that the rate of return to education of migrant people is lower than that of urban population [2]. In addition, the rate of return to education between the provinces is quite different, and it basically shows "eastmiddle-west" ladder-like distribution [3]. Women are often at a disadvantage in the labor market. 
There are wage differences in the industry [4]. Member of CPC and types of enterprise also have an impact on wages [5].

\subsection{Research Method}

So far, there have been many studies on the wage equation, of which the methods are mainly instrumental variables and ordinary least squares (OLS). However, recent years have not seen enough researches for real-time supplement of the content. This thesis aims to adopt OLS method to estimate the rate of return to education in the wage equation, the rate of return to work experience, and other factors. It also offers relevant suggestions.

\section{Theoretical Analysis, Model and Data Description}

\subsection{Model Settings and Data Sources}

In 1974, Mincer proposed the expression of standard wage equation, namely: $\ln$ (wage) $=\mathrm{c}+$ $\beta 1$ edu $+\gamma 1 \exp +\gamma 2 \exp 2+\epsilon$, of which wage is salary income; Edu is years of education; exp is working experience.

The expression is based on micro-data, reflecting the impact of educational level and working experience on the rate of return to salary income. In the past few years, most studies on wage levels have used Mincer wage equation or its extended form to conduct analysis. The thesis will also calculate the impact of various factors on salary income by extending Mincer wage equation, and the expression is as follows: $\ln$ (wage) $=c+\beta 1$ edu $+\gamma 1 \exp +\gamma 2 \exp 2+\Sigma \alpha i f i+\epsilon$, of which wage means salary income; Edu is the years of education; exp means work experience; fi means other influencing factors.

The data used in the thesis is from the follow-up report conducted by China Family Panel Studies (CFPS) in 2014, which was implemented by China Institute of Social Science Survey of Peking University. The sample covered 25 provinces/cities/autonomous regions, represented $95 \%$ of China's population, and obtained 37147 personal data [6]. A total of 7658 personal data was used after been filtered and culled.

Limited by the number of data, the thesis mainly use education level, work experience gender, region, household registration, whether being the member of CPC as the influencing factors of salary income to conduct regression analysis, through references and other researches.

\subsection{Theoretical Analysis}

Mincer is convinced that in a perfectly competitive labor market, human capital becomes the key factor that influences personal income. Years of education and work experience can serve as a measure of human capital. As a result, education level and work experience perform as explanatory variables in standard Mincer wage decision equation, and they both have positive effects on wages. That is, the improvements of education and work experience can lead to wage growth. In addition, with the continuous increase of work experience, the increase of human capital that it brings to people is diminished. For example, for a new worker, adding one year work experience enables him to familiarize with the operation, process, and matters needing attention, which is extremely helpful for the improvement of work efficiency. As for a worker with 30 years' work experience, adding one year work experience plays a limited role in the increase of work efficiency. Such being the case, Mincer also place the square term of work experience into the explanatory variables. According to the analysis mentioned above, its sign should be minus.

After that, the extended Mincer wage equation introduces more factors as explanatory variables for imperfect completion labor market, such as gender, region, household registration differences, etc. These factors may have an impact on salary income to some extent.

Gender: patriarchal somehow exists in our country. In addition, females tend to take more responsibility in the family, thus making them devote less effort at work than that of males. Therefore, there is often gender discrimination against women in labor market, which makes females have fewer wages and development opportunities than males. 
Region: the unbalanced regional development strategy results in the status quo that eastern region is rather developed and western region is backward. The gap of development degrees, on the one hand, leads to the higher level of education and broader horizon in eastern areas, increasing the level of human capital accumulation; on the other hand, such differences also bring about the discrepancy of industrial structure and capital deepening, which in turn lead to higher labor productivity in the east than that in the west and middle. Besides, these differences also lead to the higher price level and living costs in eastern China. These factors may contribute to higher wages in the eastern region.

Household registration: the household registration system is unique in China. It originates from the forging-ahead strategy in the planned economy period. The high wages in the city attract many farmers to flow to the city. A large number of mobile labor forces cause the impact on the city's original labor market. To maintain social stability, the household registration system was designed to restrict the flow of rural labor force to the cities. The development strategy focus on heavy industry and the existence of "price scissors" make the development of cities far exceeds that of rural areas. The backward development makes the human capital of rural labor force at a lower level, which is also the result of statistical discrimination. On the other hand, due to the superiority of urban residents' location in the city, they might look down upon migrant workers, making rural registered residence a negative impact on wages.

Party members: The member of CPC often represents some certain amount of political capital and potential ability advantages, which may enable him/her to gain higher status in labor market, especially in public ownership enterprises.

\subsection{Variable Declaration}

\subsubsection{Income}

Among the data used in the thesis, income refers to total income of main work in 2014, including salary, benefits, allowances, bonuses, etc. Second occupational income is not taken into consideration.

\subsubsection{Education}

according to the respondents' highest academic qualifications in the CFPS survey, they are divided into five groups such as below primary school, primary school, junior high school, senior high school/ secondary school/ technical school/ vocational school, junior college/ college and above. The questionnaire contains the option of "no need to study". Since its meaning is vague, it was excluded at the time of regression.

\subsubsection{Work Experience}

It is obtained by indirect calculation, generally being age-years of education- 6 . However, considering there are some respondents who have given up their studies before they reach the legal working age, when dealing with the variables, take the minimum of age-years of education- 6 and ageminimum of legal working age.

\subsubsection{Region}

According to the classification of regions by statistical yearbook, eastern region includes Beijing, Tianjin, Hebei, Liaoning, Shanghai, Jiangsu, Zhejiang, Fujian, Shandong, Guangdong, and Hainan. Central region covers Shanxi, Inner Mongolia, Jilin, and Heilongjiang, Anhui, Jiangxi, Henan, Hubei, Hunan, and Guangxi. Western region includes Chongqing, Sichuan, Guizhou, Yunnan, Shaanxi, Gansu, Ningxia, and Xinjiang.

\subsubsection{Household Registration}

It is divided into urban household registration and rural household registration.

\subsubsection{Member of CPC}

It is a variable that describes whether the respondent is a member of $\mathrm{CPC}$, which has a strong autocorrelation with the unit ownership system. The information of the unit ownership system is rather less, so it is not put to use. 
The data selected in the model was collected from the combination of household questionnaire and adult questionnaire, and the missing or unusable data has been excluded before regression.

Table 1. Variable Declaration

\begin{tabular}{|c|c|c|}
\hline Name & Variable & Definition \\
\hline Income & income & Main work income in 2014 \\
\hline $\begin{array}{l}\text { Years of } \\
\text { education }\end{array}$ & edu & Duration of education (year) \\
\hline \multirow{4}{*}{$\begin{array}{l}\text { Education } \\
\text { Level }\end{array}$} & \multirow{4}{*}{$\begin{array}{c}\text { Edu primary } \\
\text { Edu } \\
\text { elementary } \\
\text { Edu high } \\
\text { Edu } \\
\text { university }\end{array}$} & Primary school $(\mathrm{Yes}=1, \mathrm{NO}=0)$ \\
\hline & & Junior high school $(\mathrm{Yes}=1, \mathrm{No}=0)$ \\
\hline & & Senior high school/Secondary School $(\mathrm{Yes}=1, \mathrm{No}=0)$ \\
\hline & & College/Junior college and above $(\mathrm{Yes}=1, \mathrm{No}=0)$ \\
\hline \multirow{3}{*}{$\begin{array}{c}\text { Work } \\
\text { Experience } \\
\text { Gender }\end{array}$} & \multirow{3}{*}{$\begin{array}{c}\exp \\
\text { gender }\end{array}$} & Min of age-years of education- 6 and \\
\hline & & Age-legal working age \\
\hline & & $($ Male $=1$, Female $=0)$ \\
\hline \multirow{3}{*}{ Region } & east & Eastern region in statistical yearbook $\quad(\mathrm{Yes}=1, \mathrm{No}=0)$ \\
\hline & central & Middle region in statistical yearbook $\quad(\mathrm{Yes}=1, \mathrm{No}=0)$ \\
\hline & west & Western region in statistical yearbook $\quad(\mathrm{Yes}=1, \mathrm{No}=0)$ \\
\hline \multirow{2}{*}{$\begin{array}{l}\text { Household } \\
\text { registration } \\
\text { Member of } \\
\text { CPC }\end{array}$} & register & $\begin{array}{l}\text { Urban household registration or rural household registration } \\
\qquad(\text { city }=1, \text { countryside }=0)\end{array}$ \\
\hline & party & Whether being the member of $\mathrm{CPC}(\mathrm{Yes}=1, \mathrm{No}=0)$ \\
\hline
\end{tabular}

\section{Descriptive Statistics}

\subsection{Simple Descriptive Statistics Result}

Table 2. Simple Descriptive Statistics Result

\begin{tabular}{cccc}
\hline & Annual Income & Years of Edu & Work Experience \\
\hline Average & 29324 & 10.21 & 20.31 \\
Standard Deviation & 24530 & 3.93 & 11.91 \\
Variance & $6.02 * 10^{8}$ & 15.46 & 141.84 \\
Skewness & 3.77 & -0.50 & 0.17 \\
Kurtosis & 33.52 & 3.40 & 1.90 \\
Median & 25000 & 9 & 20 \\
\hline
\end{tabular}

As is shown in the table, the annual income scenes is 3.77 , and the statistical difference between mean and median is above 4000. The income distribution is right-skewed, indicating that high-income groups contribute a lot to the average annual income. The scenes of years of education and work experience is relatively small. Mean is not much different from median, and they are spread evenly. The average level of education is 10.21, which lies in between junior high school and senior high school. 


\subsection{Gender Difference Descriptive Statistics Result}

Table 3. Gender difference Descriptive Statistics Result

\begin{tabular}{ccccc}
\hline & & Observed Data & Mean & Standard Deviation \\
\hline \multirow{3}{*}{ Male } & Annual Income(yuan) & 4548 & 33131 & 26017 \\
& Years of education & 4548 & 10.16 & 3.72 \\
& Work Experience(year) & 4548 & 21.41 & 12.12 \\
\hline \multirow{3}{*}{ Female } & Annual income(yuan) & 3110 & 23756.36 & 20972 \\
& Years of Education & 3110 & 10.29 & 4.23 \\
& Work Experience(year) & 3110 & 18.7 & 11.41 \\
\hline
\end{tabular}

It can be seen in the data that the average annual income of women is about $28 \%$ less than that of men. Gender difference of income still remarkably exists. Namely, average income of women is far from that of men. The average duration of education of women is slightly longer than that of men, but the difference is not significant. All samples surveyed taken into consideration, the average length of education of men is 8.27 years, while that of women is 6.63 years, with a relevantly huge gap. It shows that compared with men, low-educated population takes accounts for no-income women to a large extent. The average work experience of men is 2.66 years longer than that of women, possibly because the legal retirement age of men is five years later than women. On the other hand, women generally ought to shoulder more responsibility in the field of child birth and raising, which may also make women' work experience less than that of men.

\subsection{Household Registration Difference Descriptive Statistics Result}

Table 4. Household Registration Difference Descriptive Statistics Result

\begin{tabular}{ccccc}
\hline & & Observed Data & \multicolumn{2}{c}{ Mean Standard Deviation } \\
\hline \multirow{2}{*}{$\begin{array}{c}\text { Urban household } \\
\text { Registration }\end{array}$} & Annual Income(yuan) & 3230 & 34094 & 29175 \\
& Years of education & 3230 & 12.08 & 3.47 \\
& Work Experience(year) & 3230 & 21.30 & 11.82 \\
\hline \multirow{2}{*}{ Rural household } & Annual income(yuan) & 4428 & 25844 & 19184 \\
Registration & Years of Education & 4428 & 8.85 & 3.68 \\
& Work Experience(year) & 4428 & 19.58 & 11.92 \\
\hline
\end{tabular}

The average annual income of urban household registration is $31 \%$ higher than that of rural household registration, with the years of education being about 12, namely senior high school degree. Whereas the years of education of rural household registration is about 9 , that is, junior high school degree. The difference may be related to the area where residents live. Urban household registration residents tend to center around in the cities and enjoy more abundant resources. In addition, discrimination against migrant workers may also lead to the lower income of rural household registration.

\subsection{Regional Difference Descriptive Statistics Result}

The average annual income generally showcases the decreasing trend in the order of east, central and west, but the average annual income of eastern region is remarkably higher than that of central and west region. The annual average income gap between central region and western is relatively small, which suggests that eastern region far exceeds the other two regions in terms of economic development. As for the years of education, the average years of education of eastern and central regions are almost the same. There is no significant difference in the education environment and resource allocation. However, the average years of education of western area are relatively low. There still remains a huge gap between it and eastern, central region. 
Table 5. Regional Difference Descriptive Statistics Result

\begin{tabular}{|c|c|c|c|c|}
\hline & & Observed Data & Mean & Standard Deviation \\
\hline \multirow{3}{*}{ Eastern Region } & Annual Income & 3865 & 33394 & 28745 \\
\hline & Years of education & 3865 & 10.33 & 3.91 \\
\hline & Work Experience(year) & 3865 & 20.61 & 12.30 \\
\hline \multirow{3}{*}{ Central Region } & Annual income(yuan) & 2469 & 25796 & 19042 \\
\hline & Years of Education & 2469 & 10.32 & 3.77 \\
\hline & Work Experience(year) & 2469 & 20.25 & 11.45 \\
\hline \multirow{3}{*}{$\begin{array}{l}\text { Western } \\
\text { Region }\end{array}$} & Annual income(yuan) & 1324 & 24019 & 17123 \\
\hline & Years of Education & 1324 & 9.67 & 4.25 \\
\hline & Work Experience(year) & 1324 & 19.54 & 11.55 \\
\hline
\end{tabular}

\section{Analysis of Regression Results}

\subsection{Analysis of Extended Mincer Salary Equation Regression Results}

Table 6 illustrates the results of extended Mincer salary equation, in which the uneducated level serves as the reference group. The rates of return to education of primary school, junior high school, senior high school and college are as follows, 0.177, 0.223, 0.292 and 0.757 , all of which are significant at $1 \%$ level, and they are in a sequential upward trend. Among them, the growth rates of return to education of primary school, junior high school, senior high school are not obvious, while the rate growth of college is rather remarkable than that of senior high school, which reflects the current high demand for highly educated personnel in labor market. With the popularity of nine-year compulsory education, merely holding junior high school or primary school degree may become the personal weakness.

It can be seen from the work experience and the coefficient of its square that income logarithm and work experience are still in inverted U-shaped relationship. Via the calculation of the coefficient, income logarithm achieved the maximum when work experience is about 22 years; namely the maximum is reached at the age about $40 \mathrm{~s}$, which is rather consistent with the result of CHNS survey [7]. Some of the earlier studies (1988-1995) came to the conclusion that income reached the maximum at the age about 56-60[8]. The extreme point of income on work experience functions is gradually decreasing year by year. In the previous system, the phenomenon of arrangement in order of seniority is more severe. However, in the market-oriented system, the decisive effects of marginal productivity rise gradually, and age of 40 is a period of high marginal productivity. The phenomenon illustrates the effectiveness of market-oriented reform.

In terms of other variables in extended Mincer wage equation, central region is regarded as the control group. The coefficient of the west is -0.0576 , and that of the east is 0.30 . The eastern variable is significant at $1 \%$ level, while the western variable is not significant at $5 \%$ level, but at $10 \%$ level. However, it is still in a decreasing trend of east-middle-west sequence, of which the gap between western and central region is relatively small. Whereas the eastern region is much higher than central and western region, indicating that eastern region still has a high level of development at present.

The regression coefficients of gender variables and household registration variables are 0.448 and 0.0830 , both respectively significant at $1 \%$ level, showing that they still have a relevantly large effect on wages. The regression coefficient of party member of CPC is 0.0592 , which is also significant at $10 \%$. It has some certain impacts on wage determination mechanism. 
Table 6. Extended Mincer Wage Equation Regression Result

\begin{tabular}{ccc}
\hline Variable & Coefficient & Mean square error \\
\hline Primary School & $0.177^{* * *}$ & 0.045 \\
Junior High School & $0.223^{* * *}$ & 0.041 \\
Senior High School & $0.292^{* * *}$ & 0.045 \\
College and above & $0.757^{* * *}$ & 0.050 \\
Work Experience & $0.0499^{* * *}$ & 0.0034 \\
Work Experience Square & $-0.00111^{* * *}$ & 0.00075 \\
Gender & $0.448^{* * *}$ & 0.020 \\
Eastern Region & $0.270^{* * *}$ & 0.022 \\
Western Region & $-0.0576^{*}$ & 0.030 \\
Household Registration & $0.0830^{* * *}$ & 0.023 \\
Member of CPC & $0.0592^{*}$ & 0.034 \\
\hline
\end{tabular}

Note: $* * *$, and $* * *$ indicate that they are respectively significant at $10 \%, 5 \%$ and $1 \%$ significance level.

\subsection{Difference Analysis}

\subsubsection{Regional Difference Regression Results}

Table 7. Regional Difference Regression Results

\begin{tabular}{cccc}
\hline Variable & Eastern Region & Central Region & Western Region \\
\hline Primary School & $0.206^{* *}$ & 0.120 & $0.204^{* *}$ \\
Junior High School & $0.250^{* * *}$ & $0.185^{* *}$ & $0.252^{* * *}$ \\
Senior High School & $0.347^{* * *}$ & $0.263^{* * *}$ & $0.162^{* *}$ \\
College and above & $0.847^{* * *}$ & $0.685^{* * *}$ & $0.665^{* * *}$ \\
Work Experience & $0.0517^{* * *}$ & $0.04770^{* * *}$ & $0.0555^{* * *}$ \\
Work Experience Square & $-0.00109^{* * *}$ & $-0.00110^{* * *}$ & $-0.00126^{* * *}$ \\
Gender & $0.444^{* * *}$ & $0.457^{* * *}$ & $0.445^{* * *}$ \\
Household Registration & $0.152^{* * *}$ & -0.0240 & 0.076 \\
Member of CPC & $0.146^{* *}$ & -0.00773 & 0.0440 \\
\hline
\end{tabular}
level.

Note: $* * *$, and $* * *$ indicate that they are respectively significant at $10 \%, 5 \%$ and $1 \%$ significance

When it comes to education background, the rates of return to education of primary school in eastern and western regions are relatively similar, while the regression result of central region is not significant at $10 \%$ level. The rate of junior high school descends in the order of west-east-middle, whereas the rate of senior high school and college descends ranked by east-middle-west. At present, western region is still lagging behind from the perspective of development, and its demand for talents is also more than other regions. However, its development demand may be reflected in the needs of infrastructure. Therefore, with national policy support and strong needs, the rate of return to basic education in western regions is even higher than that of eastern region. Nevertheless, the industrial structure in the west is relatively backward, and it is still dominated by traditional industries. These industries have fewer demands for highly educated talents. For many advanced talent markets, the existing system in eastern region is more mature, and the development conditions are even better as well. Apart from this, even though there are some policy encouragements, many enterprises and factories are faced with bottle-neck, leading to the fewer large-scale enterprises in western regions. As a result, in the aspect of higher education, especially in college/ junior college education, the rate of return to education in western region is the lowest in the country. 


\subsubsection{Gender Difference Regression Result}

Table 8. Gender Difference Regression Result

\begin{tabular}{ccc}
\hline Variable & Male & Female \\
\hline Primary School & $0.112^{* *}$ & $0.156^{* *}$ \\
Junior High School & $0.212^{* * *}$ & $0.128^{* *}$ \\
Senior High School & $0.197 * * *$ & $0.327^{* * *}$ \\
College and above & $0.644^{* * *}$ & $0.782^{* * *}$ \\
Work Experience & $0.0546^{* * *}$ & $0.0462^{* * *}$ \\
Work Experience Square & $-0.00117^{* * *}$ & -0.010795 \\
Eastern Region & $0.269^{* * *}$ & $0.269^{* * *}$ \\
Western Region & $-0.058^{*}$ & -0.0796 \\
Household Registration & $0.048^{*}$ & $0.153 * * *$ \\
Member of CPC & 0.0355 & 0.100 \\
\hline
\end{tabular}

Note: $* * *$, and $* * *$ indicate that they are respectively significant at $10 \%, 5 \%$ and $1 \%$ significance level.

In addition to the junior high school education degree variable, the rate of return to education of women is higher than that of men. On the one hand, since the sample is composed by the respondents with income, some women with low education degree and no income can rely on their spouses to live. On the other hand, due to the gender discrimination in the labor market, women who can enter the labor market often own high academic qualification, thus making the rate of return to education of women higher than that of men. Besides, urban household registration has a larger influence on women. Women with rural household registration are more likely to suffer from discrimination in the labor market.

The regression results reveal that men achieve the maximum income when their work experiences are 23 years, while women's are 21 years. It can be concluded from the descriptive statistical results that the average seniority of men is longer than that of women. Men tend to enter the labor market earlier and retire later. Therefore, the peak of income is reached later than women.

\section{Conclusion}

\subsection{Main Conclusion}

Based on the micro-data obtained by CFPS in 2014 and according to the extended Mincer wage equation, the thesis uses ordinary least square (OLS) to conduct regression analysis of five variables' impact on salary income. The five variables are education, work experience, gender, household registration, and whether being the member of $\mathrm{CPC}$. The results obtained are consistent with the expectation except for the variable of whether being the member of $\mathrm{CPC}$. The following conclusions are drawn based on the regression results.

(1)In general, the rate of return to education rises with the order of primary school-junior high school-secondary school/senior high school-junior college/ college. The rate of junior college/college is several times higher than that of other three education degrees. Current labor market still has a large demand for highly educated talents.

(2) There is still an inverted U-shaped relationship between salary income and work experience. The regression results showcase that salary income reaches the maximum when the work experience is about 22 years, and it has a tendency to decrease with time, indicating that the phenomenon of arrangement in order of seniority is gradually decreasing. Meanwhile, the decisive role of marginal productivity in wage determination is gradually increasing.

(3) Regional difference and gender difference have great effects on salary income. The difference between western region and central region is not obvious, but the coefficient of salary income in eastern regions is more than significant. The average income of eastern region is higher than that of 
western and central region. In addition, for basic education, especially primary and junior high school education, the rate of return to education is on the decrease with the order of east-west-central. However, for the college/junior college education, the rate of return to education decreases with the order of east-central-west.

Men's average income and work experience are both higher than those of women, but the rate of return to education of women is higher than that of men. Nowadays, obvious gender discrimination still exists in labor market. The unequal treatment of women leads to a higher rate of return to education of working women than that of men.

(4) Household registration has a notable impact in the eastern region, while there is no significant discrimination against household registration in central and western region. It also remarkably influences women, whereas its effects on men are not significant at 5\% level. Whether being the member of CPC has significant effects at $10 \%$ level, but not at $5 \%$ level.

\subsection{Policy Recommendations}

Firstly, continue to vigorously promote the development of higher education and improve residents' education level. The regression results indicate that current rate of return to education is still at a relatively high level. Labor market also has a huge demand for high-end talents. Further popularization of higher education is not only of benefit for the improving of overall quality of residents. In the long run, it can also increase resident income and improve the unequal distribution of wages.

Secondly, strengthen the input in the western region and accelerate its development. At present, the economic development of western regions is still lagging behind. Its per capital income and education level are lower than those in other regions. Consequently, it is essential to speed up the industry development in the western region. Importance should be attached to the brain gain. In order to encourage talents and enterprises to flow to the west, the high-end talents, enterprises and outstanding teaching and administrative staffs ought to be given subsides and safeguard, thus improving the education level and economic development of western regions.

Thirdly, adopt the policy that promotes equality between men and women. The rate of return to education of women is higher than that of men, which reflects the important contribution of female workers to China's economy development. However, the average income of women is still far from that of men. Female workers are more likely to become the victims of discrimination in the labor market. Therefore, policies should be adopted to reduce the occurrence of gender discrimination, so as to prevent excellent female workers from not getting reasonable social status and rewards, thus better taking the advantages of female workers in labor market to the full.

Last but not least, ensure the balance of urban and rural resource allocation. The discrimination brought out by household registration mostly occurs in the eastern region with a large amount of population inflow. The rapid population growth is more likely to cause the imbalance in resources allocation and result in discrimination against rural household registration. Reasonable allocation of resources is beneficial for rural household registration residents to obtain more living and education resources and enhance their competitiveness in the labor market. Meanwhile, it may also reduce the discrimination against rural household registration as well.

\section{References}

[1]. Wang Mayan. Differences of Employment Opportunities and Wages in Urban Labor Market: Research on Employment and Wages of Migrant Workers. P36-46.

[2]. Deng Queen. Income Differences of Urban Citizens and Floating Population, p8-15.

[3]. Zhou Guoyu. Provincial Differences of the Rate of Return to Education, p83-87.

[4]. Wang Mayan. Gender Wage Differences in China Urban Labor Market, p35-43. 
[5]. Yang, Dennis Tao. Determinants of Schooling Returns during Transition: Evidence from Chinese Cities. Journal of Comparative, p244 -264.

[6]. Xin Yu, Zhang Xiao, To Ping, Ren Qian, Sun Yan, Lv Ping, Ding Hua, Hu Jingle, Wu Qigong. China Family Panel Studies Handbook (the third edition), p5-14.

[7]. Zhang Key, China Wage and Wage Equation of Urban Labor Force in Economic Transition Period, Literary Review. P142-174.

[8]. Yang Hoisin, Wang Haibing, the Rate of Return to Education in China: 1989 -2011. P1-16. 